\title{
Systematic literature review of the impact and effectiveness of monovalent meningococcal $C$ conjugated vaccines when used in routine immunization programs
}

\author{
Myint Tin Tin Htar ${ }^{1 *}$ (D), Sally Jackson ${ }^{2}$, Paul Balmer ${ }^{3}$, Lidia Cristina Serra ${ }^{3}$, Andrew Vyse ${ }^{4}$, Mary Slack,
} Margarita Riera-Montes ${ }^{2}$, David L. Swerdlow ${ }^{3}$ and Jamie Findlow ${ }^{1}$

\begin{abstract}
Background: Monovalent meningococcal C conjugate vaccine (MCCV) was introduced into the routine immunization program in many countries in Europe and worldwide following the emergence of meningococcal serogroup C (MenC) in the late 1990s. This systematic literature review summarizes the immediate and long-term impact and effectiveness of the different MCCV vaccination schedules and strategies employed.

Methods: We conducted a systematic literature search for peer-reviewed, scientific publications in the databases of MEDLINE (via PubMed), LILACS, and SCIELO. We included studies from countries where MCCV have been introduced in routine vaccination programs and studies providing the impact and effectiveness of MCCV published between 1st January 2001 and 31st October 2017.

Results: Forty studies were included in the review; 30 studies reporting impact and 17 reporting effectiveness covering 9 countries (UK, Spain, Italy, Canada, Brazil, Australia, Belgium, Germany and the Netherlands). Following MCCV introduction, significant and immediate reduction of MenC incidence was consistently observed in vaccine eligible ages in all countries with high vaccine uptake. The reduction in non-vaccine eligible ages (especially population > 65 years) through herd protection was generally observed 3-4 years following introduction. Vaccine effectiveness (VE) was mostly assessed through screening methods and ranged from 38 to 100\%. The VE was generally highest during the first year after vaccination and waned over time. The VE was better maintained in countries employing catch-up campaigns in older children and adolescents, compared to routine infant only schedules.

(Continued on next page)
\end{abstract}

\footnotetext{
*Correspondence: Myint.TinTinHtar@pfizer.com

${ }^{1}$ Medical Development, Scientific \& Clinical Affairs, Pfizer, 23-25 Avenue Docteur Lannelongue, Paris 75014, France

Full list of author information is available at the end of the article
}

(C) The Author(s). 2020 Open Access This article is licensed under a Creative Commons Attribution 4.0 International License, which permits use, sharing, adaptation, distribution and reproduction in any medium or format, as long as you give appropriate credit to the original author(s) and the source, provide a link to the Creative Commons licence, and indicate if changes were made. The images or other third party material in this article are included in the article's Creative Commons licence, unless indicated otherwise in a credit line to the material. If material is not included in the article's Creative Commons licence and your intended use is not permitted by statutory regulation or exceeds the permitted use, you will need to obtain permission directly from the copyright holder. To view a copy of this licence, visit http://creativecommons.org/licenses/by/4.0/. The Creative Commons Public Domain Dedication waiver (http://creativecommons.org/publicdomain/zero/1.0/) applies to the data made available in this article, unless otherwise stated in a credit line to the data. 


\begin{abstract}
(Continued from previous page)
Conclusions: MCCV were highly effective, showing a substantial and sustained decrease in MenC invasive meningococcal disease. The epidemiology of meningococcal disease is in constant transition, and some vaccination programs now include adolescents and higher valent vaccines due to the recent increase in cases caused by serogroups not covered by MCCV. Continuous monitoring of meningococcal disease is essential to understand disease evolution in the setting of different vaccination programs.
\end{abstract}

Keywords: Meningococcal disease, immunization, impact, effectiveness, herd protection

\section{Background}

Invasive meningococcal disease (IMD), caused by Neisseria meningitidis, is a leading cause of bacterial meningitis and sepsis [1]. IMD is severe with high morbidity and mortality $[1,2]$ and is considered an important global health issue [3]. Five serogroups (A, B, C, W, and Y) of $N$. meningitidis have historically been responsible for most IMD cases, although striking regional differences exist with a highly dynamic epidemiology determining global distribution changes over time $[3,4]$.

An increase in serogroup $C$ invasive meningococcal disease (IMD) due to hyperinvasive sequence type 11 (ST-11) occurred in many countries during the 1990s. As cases were occurring across all ages including infants and toddlers, the currently available plain-polysaccharide vaccines were not suitable for implementation due to poor immunogenicity in children less than 2 years of age. The development of the Haempophilus influenzae type b (Hib) conjugate vaccine had successfully demonstrated the benefit of conjugation in producing a vaccine immunogenic in infants. Consequently, monovalent MenC conjugate vaccines (MCCV) were developed by multiple manufacturers and these were subsequently introduced across Europe and globally [5]. Three monovalent MCCV were licensed, two vaccines used CRM-197 as carrier protein and one used Tetanus toxoid (TT), which have been followed by three quadrivalent ACWY meningococcal conjugate vaccines (MCV4), each conjugating either CRM-197 or TT or diphtheria toxoid (DT), a monovalent meningococcal A conjugate vaccine conjugating to TT and two combination meningococcal conjugate vaccines, a Hib-MenC conjugate vaccine and a Hib-MenCY conjugate vaccine, both conjugating to TT [6]. The United Kingdom (UK) was the first country to incorporate MCCV into the routine immunization schedule in 1999, closely followed by several other countries [7-11]. MCCV is part of the national immunization program (NIP) in 17 countries in Europe [12]. While these monovalent or quadrivalent meningococcal NIPs have been largely successful in reducing the incidence of MenC IMD in these countries [13], outbreaks still occur. For example, men who have sex with men have been identified as a potential high risk group in recent years following outbreaks in Canada, the United States, Germany, France and Belgium
[14-18]. Implementation of MCCV NIP schedules have varied, with some countries focusing on infant vaccination with or without a booster dose, some vaccinating toddlers and some including catch up campaigns at time of implementation. Over time, schedules within some countries have been adapted in response to the evolving MenC epidemiology and to optimize protection beyond infancy through both direct and indirect (herd) protection. This systematic literature review aims to summarize the global evidence on the impact and effectiveness for routine vaccination with MCCV on MenC IMD, particularly from the point of view of the different vaccination schedules and strategies implemented as well as the duration of protection.

\section{Methods}

We conducted a systematic literature search for peerreviewed, scientific publications in the databases of MEDLINE (via PubMed), LILACS, and SCIELO. Search terms incorporated terms for the vaccine [((Meningococcal OR Meningit") AND Conjugate AND ("Serogroup C" OR MCC) AND (vaccine OR vaccination))], outcome [(Hospital OR Hospitalization OR Hospitalisation OR admission OR invasive meningococcal disease OR IMD)], and effect measurements [("Vaccine effectiveness" OR "odds ratio" OR "OR" OR "Relative risk" OR "RR" OR "Hazard ratio" OR HR OR Incidence OR rate OR trend OR epidemiology OR evolution)]. In PubMed, filters were used to include human studies only. Additional references were included after hand search on citations of the included studies (snowballing).

We included studies from countries where any MCCV was introduced in routine vaccination programs (i.e. included in the NIP), populations of all ages, single or multiple hospital settings, and observational study designs (e.g. cohort, case-control, surveillance-based, ecological) published from 1st January 2001 to 31st October 2017. We included all studies evaluating MCCV regardless of commercial brand. Our outcome of interest was hospitalization for MenC IMD, and measures of interest were Vaccine Effectiveness (VE) and impact. VE is estimated using an observational approach by comparing vaccinated and unvaccinated individuals in populations eligible to receive the vaccine and often uses a case- 
control or cohort study design or the screening method VE is usually calculated as 1- relative risk or odds ratio or hazard ratio and expressed as a percentage. The impact of the vaccination program is usually estimated by comparing the incidence rates of the disease in the population in the presence and absence of the program, with incidence rates before and after implementation of the program most commonly compared. The impact usually expressed as a rate reduction in incidence [19]. We included studies published in English, French, Spanish, Portuguese, Dutch, German, and Italian.

We excluded data from countries where MCCV were not part of the routine vaccination program, and studies reporting on higher valent (e.g. quadrivalent meningococcal conjugate vaccine) or combination vaccines except for studies reporting on the MenC-Hib combination vaccine in the UK and Australia, which were included. Review papers were excluded. Two reviewers (HS and MRM) screened the titles and abstracts of records identified through database searches for their relevance, based on the inclusion/exclusion criteria. In case of doubt, a third opinion was sought from a third reviewer (MTTH). The full-text review of the articles retrieved in the first screening step was conducted by a single reviewer (HS). A single reviewer performed the grey literature search (HS).

Data from the eligible full-text papers identified in the second selection step was extracted by one reviewer (SJ) using a standardized extraction form adapted from the Preferred Reporting Items for Systematic Reviews and Meta-Analyses (PRISMA) checklist. Where more than one report on the same study (population) was identified, data collected from these reports were merged into a single entry. For quality control, re-extraction of $10 \%$ of the papers was completed by a second reviewer. Data were collected on VE (i.e. VE, RR, OR, HR) and impact (IRR and incidence rate differences). Data on the population (age, size, setting, location), study design, vaccine schedule, age at vaccination and time since vaccination, case definition and diagnostic method, outcome measures and outcomes (including confidence intervals around the estimate) were collected. No formal quality assessment or evidence grading of the studies was conducted. Descriptive analysis was conducted. Metaanalysis was not considered appropriate given the different methodologies of the studies, the heterogeneity of the estimates (delay between vaccination and outcome estimation, age-group stratification, and study setting). The full protocol is available as Supplementary document 1.

\section{Results}

The initial search yielded 283 articles, 203 articles were excluded after reading the titles and abstracts. 80 articles full text were read and assessed for eligibility and 40 studies were finally included (Fig. 1). A total of 30 studies reported impact of MCCV vaccination programs and 17 studies reported vaccine effectiveness (direct effect) of MCCV. Studies came from 9 different countries; 11 from England and Wales/UK [20-30], 10 from Spain [31-40], 5 from Canada [41-45], 4 each from Brazil [46-49] and Italy [50-53], 2 each from Australia [54, 55] and the Netherlands [56, 57], and one each from Germany [58] and Belgium [59]. The MCCV were introduced as part of the routine childhood NIP in all these countries. A catch-up campaign was also implemented in UK, Spain, Brazil, Belgium, Australia and the Netherlands. A list of summary study characteristics is presented in Supplementary Table 1.

\section{Impact of MCCV programs}

A total of 30 studies in 9 countries reported the impact of MCCV NIPs on the incidence of MenC disease. Given the differences between countries in terms of prior nonconjugate vaccination program, dosing schedule, vaccination coverage, recommended ages, and the use of catch-up campaigns, we have summarized the impact per country.

\section{United Kingdom}

The UK was the first country to introduce MCCV into their NIP in November 1999 with the schedule of 3 doses at 2, 3, 4 months of age and one catch-up dose for all children $\leq 18$ years of age. In January 2002, the campaign was extended to include adults $<25$ years of age. In 2006, the infant program was reduced to 2 doses (at age of 3 and 4 months) and a booster (MenC/Hib vaccine) added at 1 year of age. In 2013, the second infant priming dose was removed and an adolescent booster dose at age 13-14 years added to the schedule (which was then 3 months, 12 months and 13-14 years of age). In 2015, MCV4 was added to adolescent routine program replacing $\mathrm{MCCV}$, and a catch-up campaign of MCV4 was offered to all aged $14-18$ years and $<25$ years of age attending university. In 2016, the infant dose at 3 months of age was removed from the schedule leaving the $\mathrm{MenC} / \mathrm{Hib}$ combination vaccine at 12 months of age. There were 6 studies evaluating the impact of the program. Four out of six studies represented earlier postMCCV periods before 2003 [20-23] and 2 studies covered later periods between 2006 and 2013 [24, 25]. No studies following the 2013 schedule change were available/included in the analysis. All the studies included were based on national surveillance data except one study in Merseyside, England [24]. During 1999-2001 the vaccine coverage was $>80 \%$ in all targeted age groups [20]. The largest impact was observed in children, with a reduction of MenC cases of $78-87 \%$ in infants $<1$ year of age, $70-98 \%$ in children $1-4$ years of 


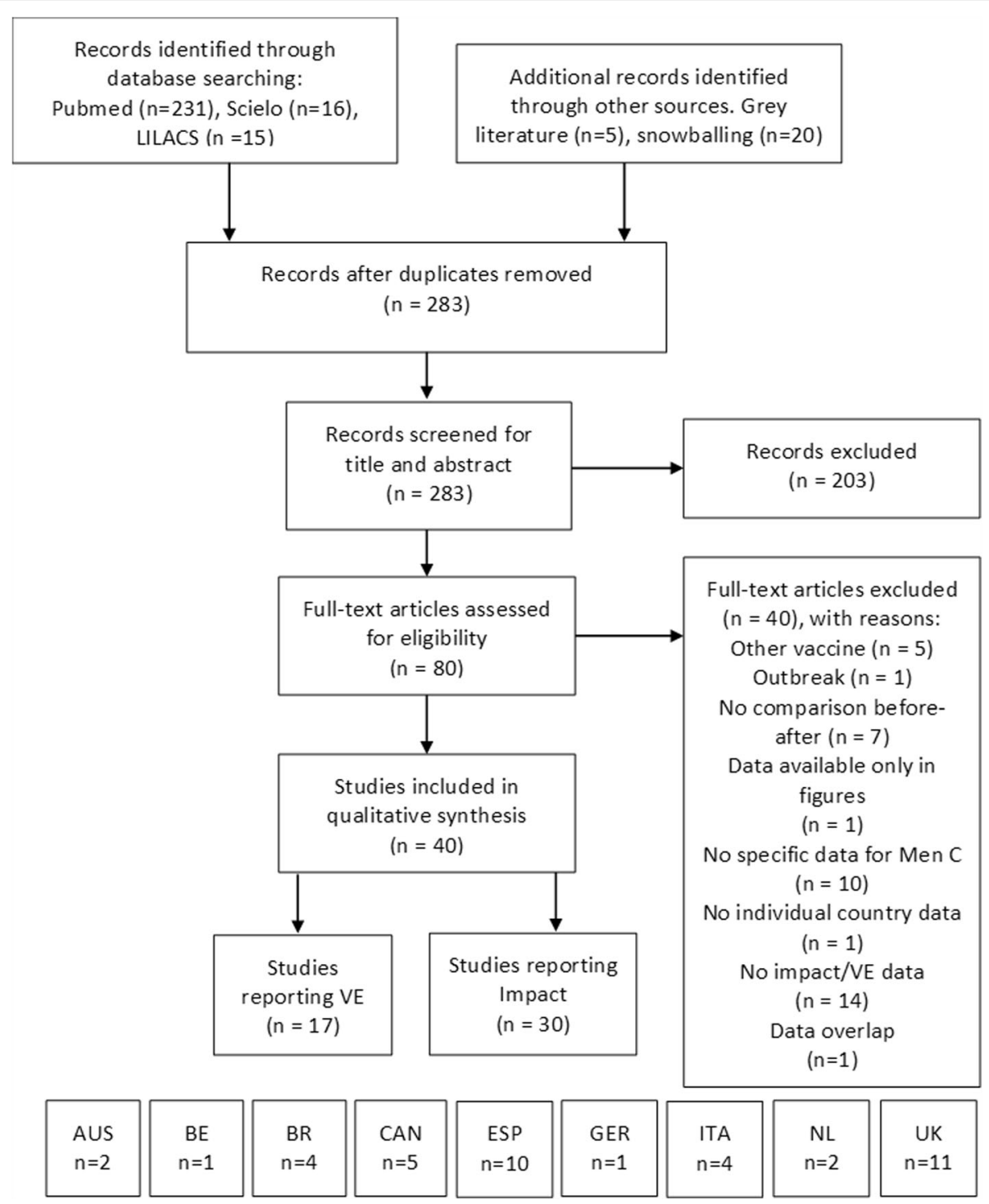

Fig. 1 Selection flowchart of included studies. Abbreviation: AUS: Australia; BE: Belgium; BR: Brazil; CAN: Canada; ESP: Spain; GER: Germany; ITA: Italy; NL: Netherlands; UK: United Kingdom

age and $79-93 \%$ in all $<18 / 20$ years of age. The largest rate reduction was observed in studies evaluating later post-MCCV periods (after 2006). The only study included in this review that evaluated impact in the initially unvaccinated population $>20$ years of age during 2 years post-vaccine implementation described an increase in incidence of $17 \%$ [25] (Fig. 2).

\section{Spain}

MCCV were introduced into the NIP in December 2000 with a 3 dose schedule at 2, 4 and 6 months of age along with a one dose catch-up campaign in children $<6$ years old except in 3 autonomous regions where a catch-up dose was given to all $<18$ years of age [60]. The catch-up campaigns differed in terms of target group, dosing schedule and periods of campaign in the different regions. In 2006, the NIP was modified to 2 doses at 2 and 4-6 months of age and a booster dose during the second year of life. One additional dose at age 12 years was added to the schedule in 2014. Since 2008 the vaccine coverage has remained $>95 \%$ for infant and $>94 \%$ for the booster dose [32]. There was a total of 7 studies from Spain (3 national studies [31-33], and one study each for Navarra [34], Galicia [35], Andalusia [36] and Catalonia regions [37]). Regardless of studies and study periods, the largest decrease of MenC cases was observed in children, with a decrease of $90-100 \%$ and $88-100 \%$ in $<1$ and $1-4$ years old respectively. A lesser decrease in MenC cases was generally observed with increasing age. An increase of $57-121 \%$ was observed in adults 25-64years of age in a study in 


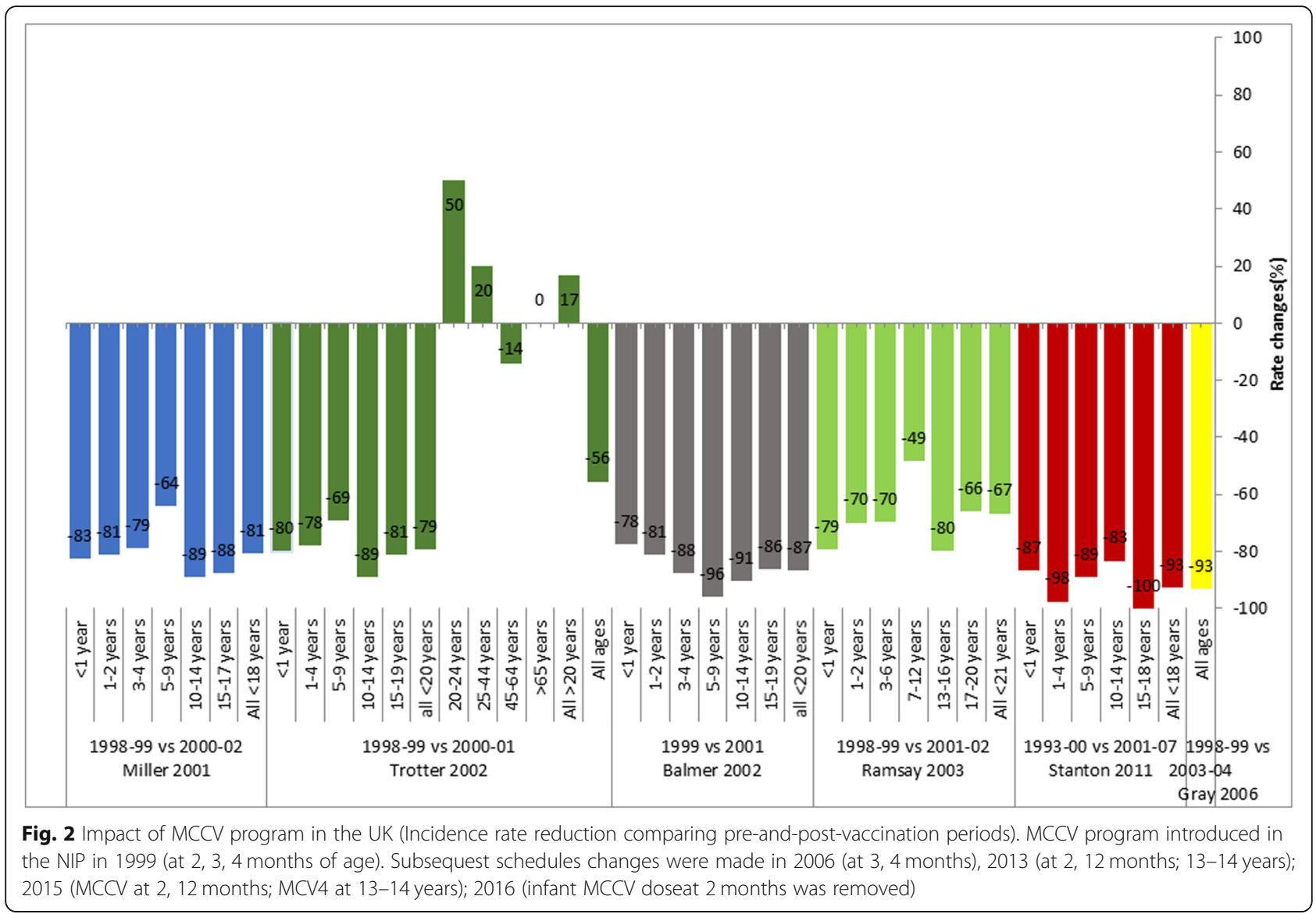

Navarra (Fig. 3a) [34]. The incidence rate was relatively low with $0.07 / 100,000$ population (1 case) in Navarra before the MCCV program. A higher MenC incidence rate was observed in later periods (2004-2014) with $0.16 / 100$, 000 population (6 cases) compared to earlier periods (2001-2003) with $0.11 / 100,000$ population (1 case) [34]. In summary in Spain, following routine vaccination with $\mathrm{MCCV}$, MenC cases were reduced by $45-96 \%$ in all ages, with an apparent larger reduction in later periods compared to earlier post-introduction period (Fig. 3b).

\section{Brazil}

MCCV were introduced into the NIP in November 2010 with a schedule of 3 doses at 3, 5 months and 12-15 months of age. No catch-up was implemented at national level, but most states implemented catch-up vaccination for children $<2$ years of age [46]. In Salvador, $\mathrm{MCCV}$ were introduced into the regional immunization program (Bahia federative state) in February 2010 with a 3 -dose schedule at 2 and 4 months and a booster during the second year of life. One catch-up dose was given to all children $<5$ years of age. Due to an unusually high number of cases and deaths, mass vaccination with a single dose of MCCV was offered to all 10-24 years old Salvador city residents during May-August 2010 [47].
Three studies were included from Brazil (Salvador City [47], Federal District [48] and the whole Brazil except Salvador city [46]). Within 4 years of MCCV introduction, there was a reduction of MenC cases of $65-100 \%$ in children $<5$ years of age, with $80 \%$ reduction in all ages despite some increases in older children and young adults (Fig. 4).

\section{Other countries}

Canada Differences in local disease epidemiology and programmatic considerations led to a variety of schedules being used in different provinces. MCCV were introduced into the immunization programs of all provinces and territories except Nunavut during 20012005 with 3 doses at 2, 4, and 6 months of age, and a modified schedule ( 2 doses at least 4 weeks apart for children 4-11 months old) [44]. However, during 19992001, mass vaccination campaigns using non-conjugate or conjugate polysaccharide vaccines were implemented to contain regional or local outbreaks [61]. All estimates from the 4 studies included described a reduction of MenC cases regardless of region, age and study period. Three studies described a reduction of $10-79 \%$ in early post-MCCV periods (before 2006) (Fig. 5) [41-43]. 


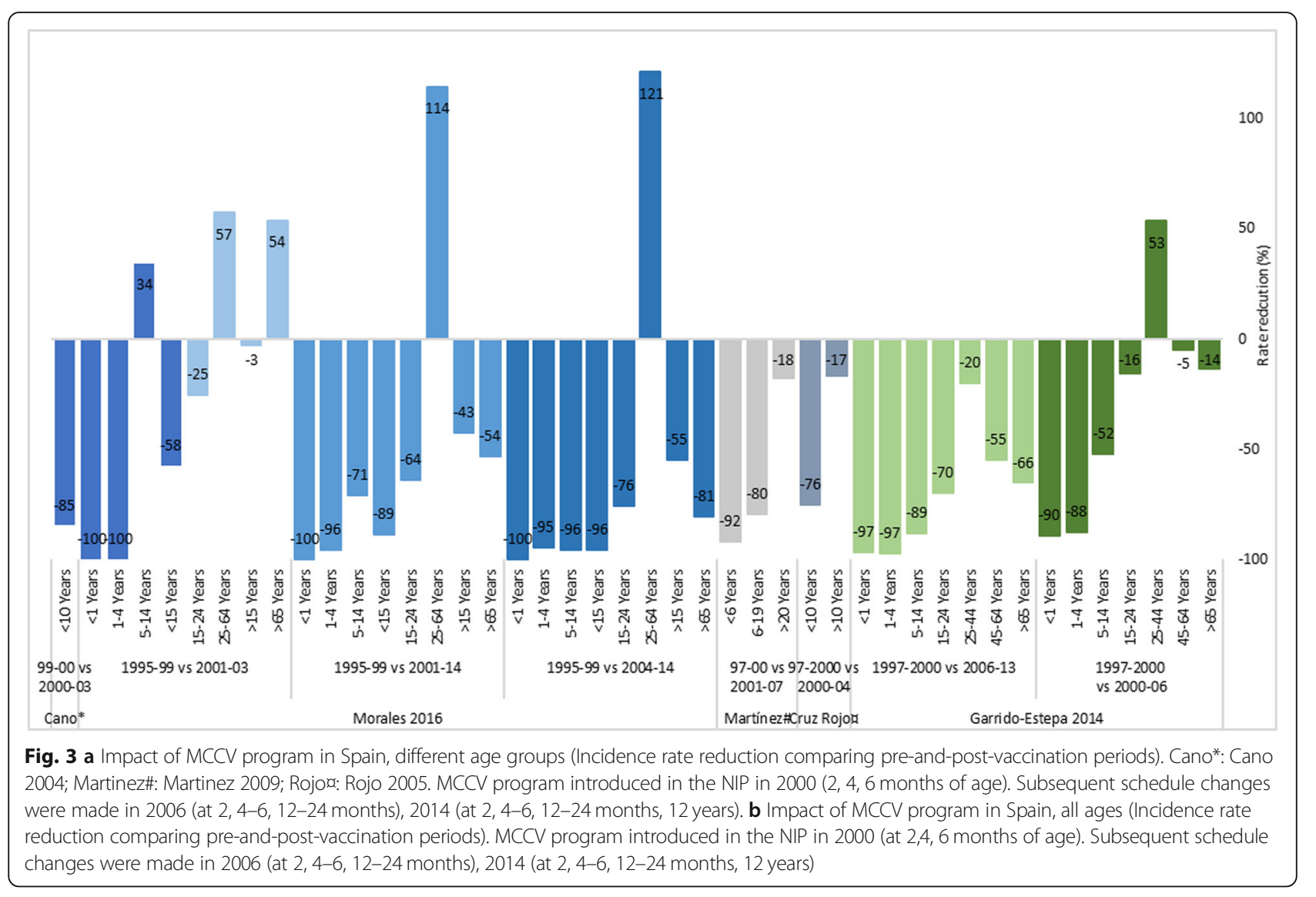

However, one study describing later periods, between 2002 and 2012 depending on the provinces, reported $79-94 \%$ reduction in all ages. The incidence decreased from 0.10 to $<0.05 / 100,000$ population in all ages in 2012, 8 years following the start of the program with a significant reduction of $14 \%$ per year. The largest decrease $(83 \%)$ was observed in the 15-24 years age group (data not shown in the Fig. 5) [44]. All provinces and territories in Canada have since introduced a routine adolescent meningococcal vaccine dose (either MCCV or MCV4) in 2007, with the exception of Alberta (introduced in 2010) and Quebec (2013) [44].

Australia MCCV were introduced into the NIP in 2003 with a single dose at 12 months of age and a catch-up dose for individuals aged 2-19 years. Seventy-six percent of the eligible population received the vaccine between 2003 and 2012. The highest coverage, 93\%, was in children < 1 year of age and the lowest, $22 \%$, in school leavers (18-19 years of age). Two studies included reported a significant reduction of $85-100 \%$ in different age groups (Fig. 5). This decrease in incidence was observed just 1-2 years after the program start and the low incidence rate was sustained in the following years (data not shown) $[54,55]$.

\section{Europe}

Belgium MCCV were introduced into the Belgian NIP in 2002 as one-dose at $12-15$ months of age. A one-dose catch-up campaign was implemented for all children 15 years old in the Wallonia region and for 1-18 years old in the Flanders region because there had been a steeper rise in incidence in Flanders [59]. We identified a single study describing the impact reporting a significant reduction in cases within all age groups from 2001 to 2004 with a $92 \%$ reduction in Flanders and $77 \%$ reduction in Wallonia (Fig. 5) [59].

Germany MCCV were introduced into the routine NIP in 2006 as a single dose in the second year of life. While a catch-up dose was recommended in all children $<18$ years of age, a coordinated catch-up campaign was not undertaken. Vaccine coverage was $70 \%$ in children entering school in 2010. The annual incidence rate decreased from 0.26 to $0.10 / 100,000$ in $<25$ years of age between 2003 and 2010. Thereduction was more pronounced in regions with higher vaccine coverage compared to those with low vaccine coverage and in vaccine eligible ages with the annual reduction rate of $19 \%$ in $1-$ 


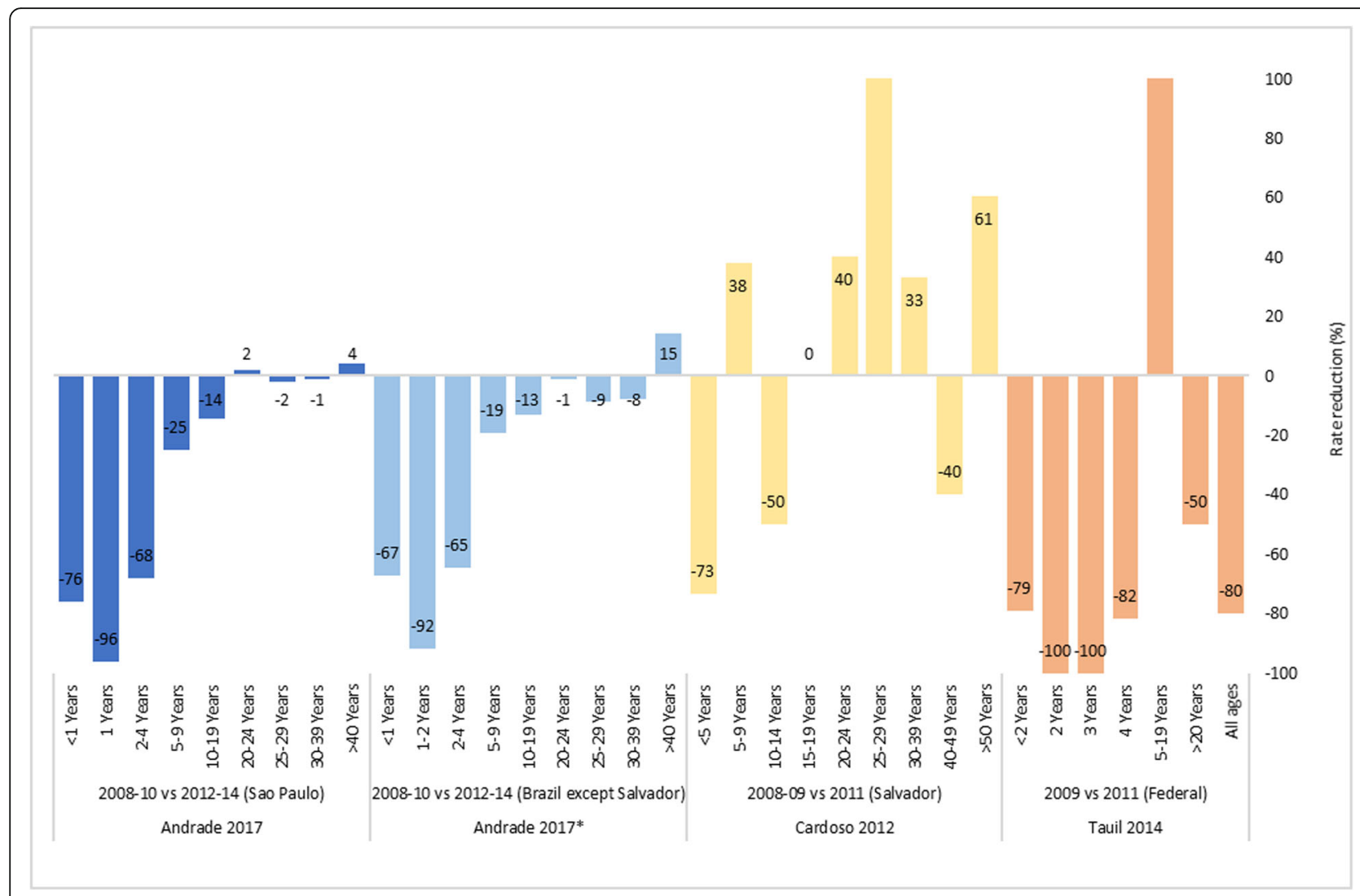

Fig. 4 Impact of MCCV program in Brazil (Incidence rate reduction comparing pre-and-post-vaccination periods). *Brazil except Salvador. MCCV program introduced in the NIP in 2010 (at 3, 5, 12-15 months of age)

5 years old compared to $9 \%$ in individuals $15-24$ years olds [58].

Italy $\mathrm{MCCV}$ were introduced into regional immunization programs during 2005-2007 with the schedule of a single dose at 13-15 months of age and a catch-up at 11-18 years of age [50]. The vaccine coverage varied widely from 37 to $93 \%$ among regions. A significant reduction of MenC cases in all ages was observed across all 3 out of 4 studies included with the highest impact in children $<5$ years of age (70-100\% reduction) and the least decrease in adults over 65 years old (21\%) during 2006-2012 compared to the period before 2005 (Fig. 5) [50, 51, 53]. One study reported the decrease in all ages but with a higher impact in children $<5$ years old between 2008 and 2009 and 2012-2013 [52].

The Netherlands MCCV were introduced into the NIP as a single dose at 14 months of age following a mass MCCV vaccination campaign in 2002 for all $1-18$ years old. Vaccine coverage reached $94 \%$ in the target population. There was a significant decrease of $99 \%$ in the vaccine-eligible population and $93 \%$ in non-vaccineeligible populations from 1998 to 2002 to 2008-2012
[57]. The overall incidence rate decreased significantly from $17.3 / 100,000$ population during the epidemic in 2001 to $0.06 / 100,000$ population in 2012 [56] (Data not shown).

\section{Effectiveness}

A total of 17 studies from 5 countries were included in the vaccine effectiveness review, 10 used the screening method to evaluate VE $[20,21,26-30,32,34,38,39,47$, 53], 5 were retrospective cohort studies (Spain and Quebec-Canada) [22, 29, 33, 34, 45] and 2 were casecontrol studies [26, 49] (Supplementary Table 1). Most of the studies using cohort or case-control designs, also estimated VE using the screening method. Most studies described several VE estimates according to different age groups, schedules and time since vaccination. A total of 147 VE estimates were available (53 from the UK, 79 from Spain, 12 from Canada, 2 from Brazil and 1 from Italy) (Table 1, Fig. 6, Fig. 7, Supplementary Figure 1). Of 147 VE estimates, 138 are statistically significant. A total of 146 of the 147 estimates described positive vaccine effectiveness ranging from 34\% (95\% CI: - 168; 83) (in children < 1 year for $>2$ years post-vaccination, Canada) to $100 \%$ (95\% CI: 100; 100) (5 estimates from 


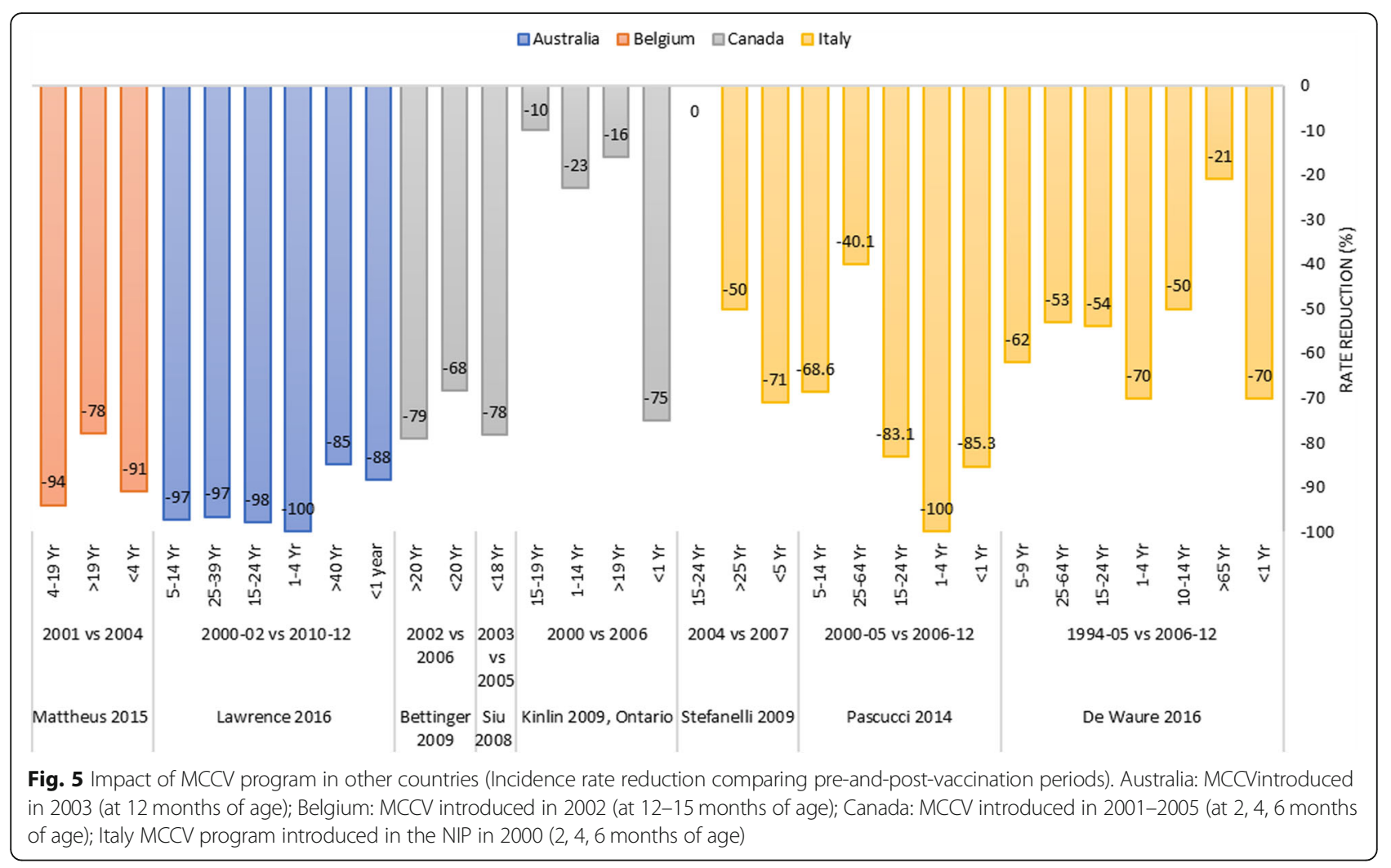

Table 1 MCCV effectiveness within and over 1 year following vaccination of included studies

\begin{tabular}{|c|c|c|c|}
\hline \multirow[t]{2}{*}{ Country, study period (References) } & \multirow[t]{2}{*}{ Schedule and at age at vaccination } & \multicolumn{2}{|c|}{ Vaccine effectiveness $(95 \% \mathrm{Cl})$; time post-vaccination } \\
\hline & & $\leq 1$ year & $>1$ year \\
\hline \multicolumn{4}{|l|}{3 doses } \\
\hline UK, 2000-2004 (Trotter 2004) [30] & Routine 3 doses (at 2, 3 and 4 months) & $93 \%$ (67 to 99$)$ & $-81 \%(-7430$ to71) \\
\hline UK, 2000-2009 (Campbell 2010) [27] & Routine 3 doses (at 2, 3, and 4 months) & $97 \%$ (91 to 99$)$ & $68 \%(-63$ to 90$)$ \\
\hline Spain 2001-2013 (Garrido-Estepa 2014) [32] & Routine 3 doses (at 2,4 and 6 months) & $98 \%$ (95 to 99$)$ & $81 \%$ (67 to 90$)$ \\
\hline Spain 2001-2013 (Garrido-Estepa 2014) [32] & Routine 3 doses (at 2,5 and > 12 months) & $100 \%$ (98 to 100$)$ & $89 \%(-23$ to 99$)$ \\
\hline Spain 2001-2013 (Garrido-Estepa 2014) [32] & Routine $1-3$ doses (at < 20 years) & $99 \%$ (98 to 99 ) & $91 \%$ (88 to 93$)$ \\
\hline \multicolumn{4}{|l|}{2 doses } \\
\hline UK, 2000-2004 (Trotter 2004) [30] & Catch-up 2 doses (2 doses at 5-12 months) & $87 \%$ (11 to 99$)$ & $82 \%$ (-8 to 97$)$ \\
\hline UK, 2000-2009 (Campbell 2010) [27] & Catch-up 2 doses (2 doses at 5-12 months) & $91 \%(-8$ to 100$)$ & $84 \%$ (31 to 97 ) \\
\hline Spain 2001-2013 (Garrido-Estepa 2014) [32] & Catch-up 2 doses (at $1-5$ years) & $99 \%$ (94 to 100$)$ & $91 \%$ (69 to 97$)$ \\
\hline \multicolumn{4}{|l|}{1 dose } \\
\hline UK, 2000-2004 (Trotter 2004) [30] & Catch-up 1 dose (at 1-2 years) & $88 \%$ (65 to 96$)$ & $61 \%(-327$ to 94$)$ \\
\hline UK, 2000-2004 (Trotter 2004) [30] & Catch-up 1 dose (at 3-4 years) & $98 \%$ (90 to 100$)$ & 93\% (78 to 98$)$ \\
\hline UK, 2000-2004 (Trotter 2004) [30] & Catch-up 1 dose (at 11-16years) & $96 \%$ (89 to 99$)$ & $90 \%$ (77 to 96$)$ \\
\hline UK, 2000-2009 (Campbell 2010) [27] & Catch-up 1 dose (at 1-2 years) & $89 \%$ (64 to 98$)$ & $71 \%(-40$ to 93$)$ \\
\hline UK, 2000-2009 (Campbell 2010) [27] & Catch-up 1 dose (at 3-18 years) & $96 \%$ (92 to 99$)$ & $93 \%$ (87 to 96$)$ \\
\hline Spain 1999-2004 (Larrauri 2005) [39] & Catch-up 1 dose (at 7 months-5 years) & $100 \%$ (98 to 100$)$ & $94 \%$ (71 to 99$)$ \\
\hline Spain 2001-2013 (Garrido-Estepa 2014) [32] & Catch-up 1 dose (at 6-12 months) & $99 \%$ (95 to 100$)$ & $93 \%$ (87 to 96$)$ \\
\hline Spain 2001-2013 (Garrido-Estepa 2014) [32] & Catch-up 1 dose (at 6-20 years) & $100 \%$ (100 to 100$)$ & $96 \%$ (91 to 98$)$ \\
\hline
\end{tabular}




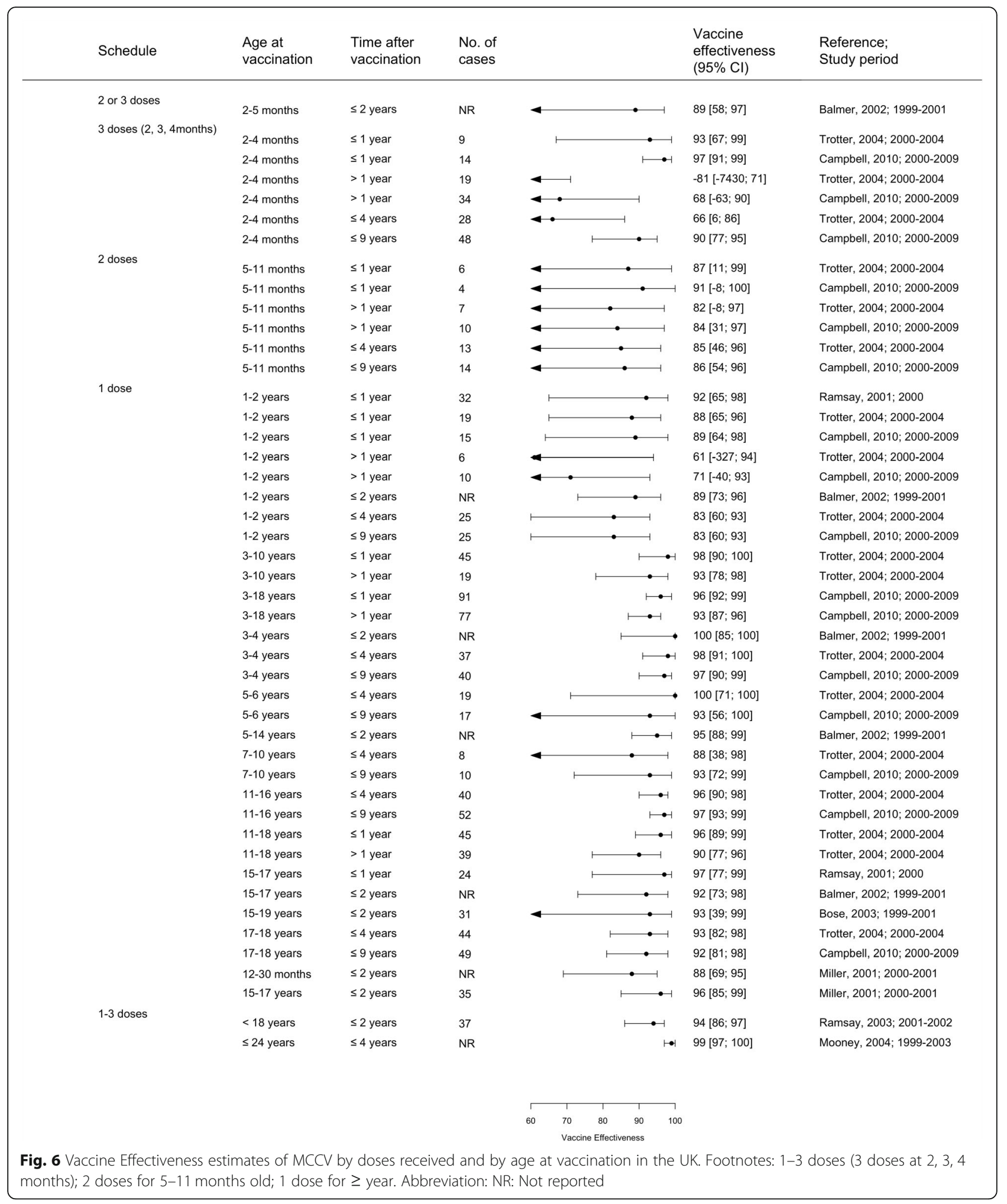

UK, Spain and Brazil) [20, 30, 32, 33, 47] and only one estimate reported negative effectiveness $(-81 \%$; $95 \%$ CI: - 7430; 71) in UK children more than 1 year following vaccination at 2-3-4 months of age [30]. The same study reported a VE of 93\% (95\% CI: 67\%;99\%) for these children within the 12 months immediately following vaccination [30]. Campbell and colleagues [27] reported data from an extension of this earlier study 


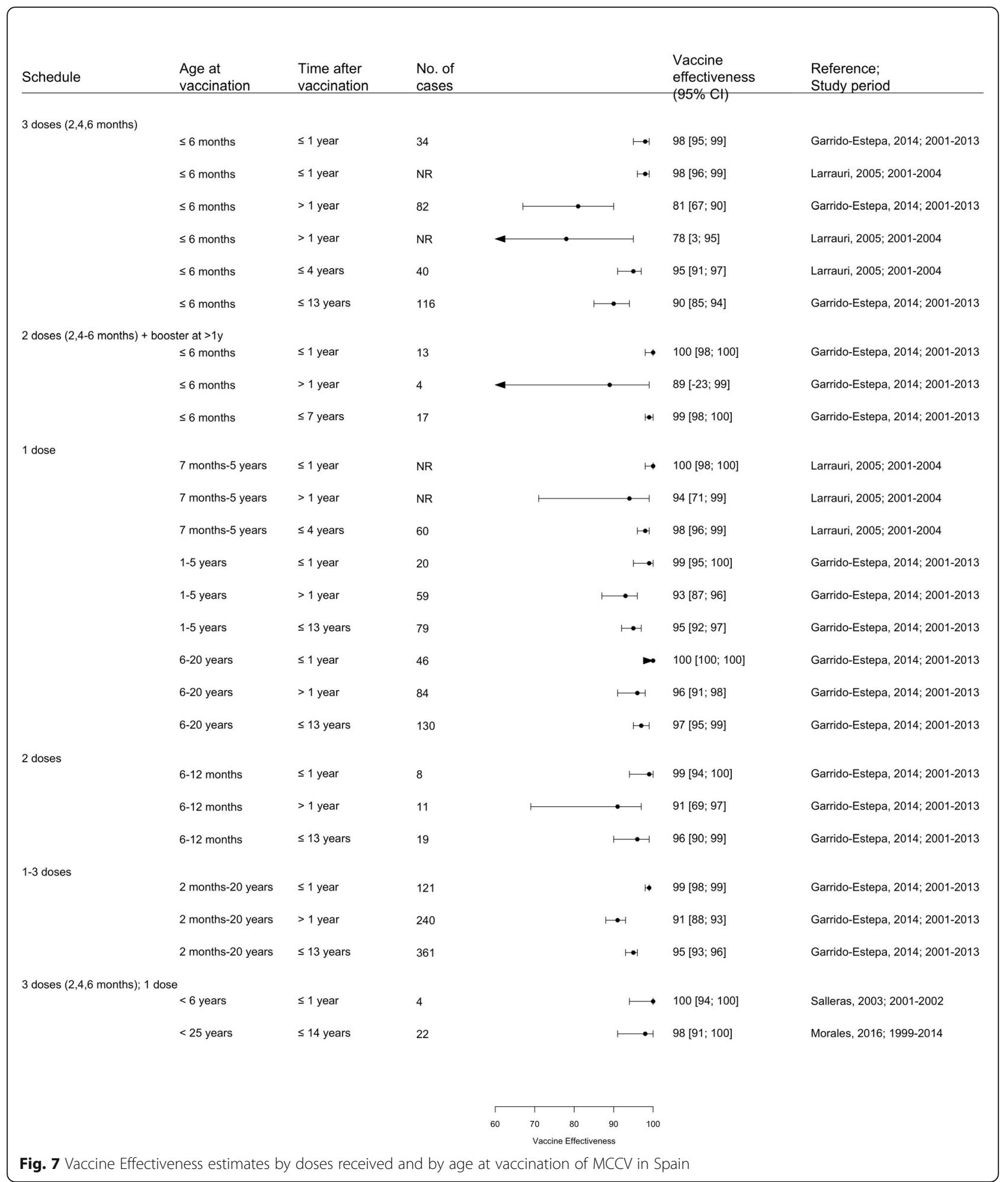

incorporating a larger number of subjects vaccinated at 2-3-4 months of age with a VE of $68 \%$ (95\% CI: - 63; 90) more than 1 year following vaccination. Of 146 positive VE estimates, 4 from the UK, 1 from Spain and 3 from Canada showed statistical non-significance.
Four studies (2 from each of the UK and Spain) specifically evaluated the VE over time $(\leq 1$ year versus $>1$ year) to determine if waning protection occurred (Table 1) [27, 30, 32, 39]. While there were, to some extent, overlapping $95 \% \mathrm{CI}$, the $\mathrm{VE}$ was generally higher 
when evaluated within 1 year of vaccination (range of 78 to $100 \%$ ) compared to those for $\geq 1$ year since vaccination (range of -81 to $98 \%$ ) regardless of age at vaccination, dosing schedule or program (routine or catch-up programs). Wide confidence intervals were usually observed in analyses evaluating $\mathrm{VE}>1$ year postvaccination (due to small number of cases) (Figs. 2, 3, supplementary figure 1). One study in Spain reported the waning VE of $50 \%$ after 10 years in young infants while those vaccinated with one dose at 12-19 years old maintained the effectiveness [38]. One study in Canada also evaluated VE over time, reporting a decline from 83 to $34 \%$ when measured within 2 years and $>2$ years after vaccination, respectively. The VE of catch-up doses in adolescents ranged from 92 to $98 \%$ [45]. No significant differences in VE estimates were observed between countries, vaccine schedules and population studies, but routine schedules where at least one dose was administered during the second year of life or catch up programs had better sustained VE in the long term. Metaanalysis was not performed due to heterogeneity in study characteristics, vaccine schedules evaluated and the study populations.

\section{Discussion}

This is the first literature review confirming the overall VE and impact of MCCV when introduced into country wide NIPs. MCCV were originally licensed on the basis of the serological correlate of protection, since the low incidence rate of MenC IMD precluded the conduct of efficacy trials. Although MCCV are proven highly immunogenic and elicit Serum Bactericidal Antibody (SBA), in the absence of clinical efficacy studies, post-licensure effectiveness studies are of particular relevance [62, 63].

This review has illustrated high and statistically significant VE of MCCV in 138 out of 147 estimates. The overall VE ranged from 38 to $100 \%$ in vaccine eligible populations regardless of the time since vaccination, or the dosing schedule (routine or catch-up doses) except for one estimate of $-81 \%$ (95\% CI: -7430 to 71$)$ at $>1$ year following a 3-dose infant schedule. The majority of VE estimates were from children $<5$ years of age due to NIPs often being implemented in infants and toddlers. These VE estimates tended to be higher than in adolescents, particularly during the first year following vaccination and may be related to the higher uptake often seen in the younger age groups. It is not unexpected because persistence of immune responses is greater in adolescents compared to infants during the clinical studies. Regarding VE over time, the estimates were consistently higher for those evaluated within 1 year of vaccination, relative to those evaluated after 1 year, regardless of the study type, dose and country [38]. These findings are consistent with decreases in the proportions of individuals with protective SBA titres overtime following vaccination in clinical studies [64-66]. The requirement for the maintenance of protective levels of circulatory anti-MenC SBA to confer continued protection was clearly demonstrated following MCCV implementation by the decreasing VE, especially where infant vaccination alone was employed. This was subsequently understood to be due the insufficiency of immunological memory to provide a response of sufficient rapidity to prevent infection and mirrored that already observed following Hib vaccine implementation $[67,68]$.

From a public health perspective, significant and immediate reduction of MenC incidence was consistently observed in vaccine eligible ages in all countries with high vaccine uptake either routine only and / or with catch-up campaign. The reduction in non-vaccine eligible ages (especially population $>65$ years) through herd protection was generally observed following 3-4 years of introduction.

Along with changes in meningococcal disease epidemiology, vaccination policies have changed over time, either as changes in schedule or more recently due to switching from monovalent conjugate to quadrivalent conjugate vaccines. In the UK, Ireland and Spain, a 3 dose infant series without a toddler booster dose $(3+0)$ was initially introduced coupled with a mass catch up campaign. Significant reductions of MenC cases first in vaccine eligible followed by non-vaccine eligible ages were observed. The vaccine schedule was changed to a 2 dose primary series and a toddler booster dose $(2+1)$ in the UK and Spain in 2006 [69] and in Ireland in 2008. Despite the changes, continuous decreases of MenC cases were observed. In England, the reported cases of MenC IMD had significantly reduced from 883 cases in 1998-1999 to about 30 cases in 2014-2015 ( 97\% reduction) with $0-1$ cases in infants during 2012-2016. In Ireland, reported MenC cases decreased from 139 cases in 2000 to $0-1$ cases in $2012-2013$ ( 100\% reduction). In Spain, about $90-100 \%$ reduction of MenC cases were observed in children $<5$ years old [31, 32, 34, 37]. However, following recent schedule changes from $2+1$ to single doses in infants, toddlers and adolescents $(1+1+$ 1) in the UK in 2013 and in Ireland in 2015 and the subsequent removal of the infant dose in the UK in 2015, re-emergence of MenC has been observed in the UK and Ireland. In the UK, the total reported MenC cases increased from 0 to 33 cases in infants and from 33 to 64 cases in all ages between 2012 and 2013 and 20172018 [70]. The driver of this increase is not fully clear but is likely associated with the increased reliance on herd protection as a driver of population control rather than individual or direct protection. Other countries such as Australia, Belgium, Italy, the Netherlands, Canada, Germany and France have introduced a single 
dose of MCCV in infants or toddlers into the NIP along with mass catch-up campaigns. Countries reaching a high vaccine uptake soon after introduction resulted in a corresponding quick and significant reduction in MenC cases. This is exemplified by Australia, where only 3 cases were reported in 2016 following the 2003 introduction of a single dose of MCCV at 12 months of age with a catch-up programme for 2-19 years old [71]. Similarly in the Netherlands, zero and 6 cases were reported in children $<14$ years and all ages respectively in 2016 [72]. In France, despite the introduction of MCCV since 2010 , the vaccine uptake was still only $39 \%$ in children 5 months of age and at $73 \%$ in children $<2$ years of age in January 2017. Meanwhile a significant increase of MenC was observed especially in infants between 2010 and 2016. As consequences, routine infant schedule was changed from one dose ( $<12$ months of age) to 2 doses (5 and 12 months of age) in May 2017. An immediate decrease in MenC cases was observed in infants while cases continued to increase and became the most prevalent serogroup in adults $>25$ years of age [73]. This resulted in the implementation of a catch-up programme for 1-24 years old unvaccinated individuals in 2018 [74]. In Germany, a gradual decrease in MenC cases was already observed prior to the introduction of the program. However, the decrease was more pronounced and accelerated in regions with high vaccine uptake $(>74 \%)$ compared to those with lower uptake $(<61 \%)$ [58]. In Italy, a significant reduction was observed immediately following MCCV introduction whilst the vaccine uptake varied from 35 to $75 \%$ according to regions. Recently there were some clusters of MenC cases described in adolescents in 2015-2016 in Tuscany where the vaccine uptake was $<70 \%$ in 2014 [75].

In recent years, meningococcal serogroup W (MenW) has been an increasing cause of disease across all age groups and in many geographically dispersed countries $[69,76,77]$. As a direct consequence quadrivalent ACWY vaccines have been added as a single adolescent dose to induce herd protection into the immunization programs of countries including the UK (2015), Ireland (2016), the Netherlands (2018), Spain and Australia (2019). It is also noteworthy that a quadrivalent meningococcal ACWY vaccine, without prior monovalent vaccine use, was introduced in the NIP in the United States in 2005 with one dose at the age of 11-12 years adolescent [78]. In 2010, a booster dose was added at age of 16 years following a study describing the waning effectiveness beyond 5 years post-vaccination [79].

This review had several limitations. First, a meaningful meta-analysis on VE estimates was not feasible. This was because the studies were heterogenous in terms of schedules, age at vaccination and study methods used [80]. In addition, immunization programs (choice of vaccine and scheduling) were constantly changing over time even within a country along with serogroup evolution and affected populations. Secondly, the review included only published papers. In most European countries, the latest disease data were reported only in publicly available reports from national and supranational surveillance but not necessarily in published papers. Therefore, the data from Ireland, France were not captured in the analysis while they are detailed and described in the discussions. In addition, the majority of data included in this review for UK and Germany are now historical and relate to the period before 2010 (Supplementary Table 1) with limited contemporary data reflecting the currently employed schedules which have changed from those originally implemented. Thirdly, 13 out of $17 \mathrm{VE}$ studies included in the review used exclusively the screening method which compared the national vaccine coverage for $\mathrm{MCCV}$ to MenC cases in vaccine eligible ages in the general population where individual vaccination status is known. This method is usually non-expensive and practical since it allows rapid estimation of VE using readily available surveillance data. However, it is relatively sensitive to errors (even minor) in input parameters such as incidence of the disease and the accuracy of the vaccine coverage rate in the population and relies on the availability of high quality surveillance data for these inputs. Usually the incidence data are collected for purposes other than for the study specifically and the age-specific vaccine coverage estimates may not be sufficiently accurate in many study settings $[68,81]$. While MenC cases are severe enough to have an appropriate diagnosis for all suspected cases and appropriately reported, the vaccine coverage rate in vaccine eligible ages could certainly be a limitation for several studies. Lastly, three MCCV have been licensed and the results have been collectively presented irrespective of the vaccine used. Whilst in some countries, the results discussed here have been generated by a single MCCV, there are other countries where multiple vaccines have been used concurrently or consecutively during a particular study period and even countries where MCCV used has varied on a regional basis. Differences in the immunogenicity of MCCV vaccines have been reported in terms of the proportions achieving protective SBA levels and the persistence of these protective levels which could translate to differences in VE $[82,83]$.

\section{Conclusions}

MCCV are highly effective, showing a substantial and sustained decrease in MenC cases in countries using them and achieving a high vaccine uptake. VE waned over time, but protection was maintained at the population level in countries with high vaccination coverage rate especially where catch-up campaigns were originally 
and effectively implemented. Epidemiology of meningococcal disease is in constant transition, and vaccination programs are extending towards adolescent programs to impart herd protection and higher valent vaccines due to the recent increases in serogroups not included in MCCV such as MenW and Y. Continuous monitoring of meningococcal disease and their genomic profile is an essential part in understanding the disease evolution along with the vaccination programs.

\section{Supplementary Information}

The online version contains supplementary material available at https://doi. org/10.1186/s12889-020-09946-1.

Additional file 1. Full protocol.

Additional file 2: Supplementary figure 1. Vaccine effectiveness of MCCV in other countries. Supplementary Table 1. Summary

characteristics of the studies included in the review.

\section{Abbreviations}

DT: Diphtheria toxoid; HR: Hazard ratio; IMD: Invasive meningococcal disease; IRR: Incidence rate ratio; MCCV: Monovalent MenC conjugate vaccines; MCV4: ACWY meningococcal conjugate vaccines; MenC: Meningococcal serogroup C; NIP: National Immunization Program; OR: Odd ratio; RR: Relative risk; TT: Tetanus toxoid; VE: Vaccine Effectiveness

\section{Acknowledgements}

Authors would like to thank Hans Scheers (P-95) for support in protocol development, literature search and data extraction; and Maria Alexandridou (P-95) and Tom De Smedt (P-95) for support with data analysis.

\section{Authors' contributions}

MTTH was involved in the design of the study, data analysis, data interpretation, and drafting the manuscript. SJ was involved in data extraction, data interpretation and drafting the manuscript. MRM was involved in the design of the study, data analysis, data interpretation, and drafting the manuscript. PB, LCS, AV, MS, JF, DLS were involved in the design of the study, data interpretation and reviewing of the drafts. All the authors had reviewed and approved the final version of the draft.

\section{Funding}

The analysis was fully funded by Pfizer Inc. MTTH, PB, LCS, AV, JF, DLS were Pfizer employees and they took part in the design of the study and collection, analysis, and interpretation of data and in writing the manuscript.

\section{Availability of data and materials}

Not applicable.

Ethics approval and consent to participate

Not applicable.

\section{Consent for publication}

Not applicable.

\section{Competing interests}

M. Tin Tin Htar, L.C. Serra, A. Vyse, J. Findlow, D. L. Swerdlow, P. Balmer are employees of Pfizer Inc. and hold company shares. S. Jackson and M. RieraMontes are employees of P-95 Epidemiology and Pharmacovigilance, Leuven, Belgium and this work was funded by Pfizer. M. Slack has received personal fees from GSK, Pfizer, AstraZeneca and Sanofi Pasteur as a speaker at international meetings and as a member of advisory boards (outside the scope of the submitted work). She has also worked as a contractor for Pfizer.

\section{Author details}

${ }^{1}$ Medical Development, Scientific \& Clinical Affairs, Pfizer, 23-25 Avenue Docteur Lannelongue, Paris 75014, France. ${ }^{2}$ P95 Epidemiology and
Pharmacovigilance, Leuven, Belgium. ${ }^{3}$ Medical Development, Scientific \& Clinical Affairs, Pfizer, 500 Arcola Road, Collegeville, PA 19426, USA. ${ }^{4}$ Medical Development, Scientific \& Clinical Affairs, Pfizer, Surrey, UK. ${ }^{5}$ School of Medicine, Griffith University Gold Coast campus, Southport, Queensland 4222, Australia.

Received: 21 January 2020 Accepted: 19 November 2020

Published online: 09 December 2020

\section{References}

1. Alonso JM, Gilmet G, Rouzic EM, Nassif X, Plotkin SA, Ramsay M, Siegrist CA, Stephens DS, Teyssou R, Vogel U. Workshop on vaccine pressure and Neisseria meningitidis, Annecy, France, 9-11 March 2005. Vaccine. 2007; 25(21):4125-9.

2. Strifler L, Morris SK, Dang V, Tu HA, Minhas RS, Jamieson FB, Deeks SL, Crowcroft NS, Sander B. The Health Burden of Invasive Meningococcal Disease: A Systematic Review. J Pediatr Infect Dis Soc. 2016;5(4):417-30.

3. Harrison LH, Trotter CL, Ramsay ME. Global epidemiology of meningococcal disease. Vaccine. 2009;27(Suppl 2):B51-63.

4. Halperin SA, Bettinger JA, Greenwood B, Harrison LH, Jelfs J, Ladhani SN, Mclntyre P, Ramsay ME, Sáfadi MA. The changing and dynamic epidemiology of meningococcal disease. Vaccine. 2012;30(Suppl 2):B26-36.

5. Trotter CL, McVernon J, Ramsay ME, Whitney CG, Mulholland EK, Goldblatt D, Hombach J, Kieny MP. Optimising the use of conjugate vaccines to prevent disease caused by Haemophilus influenzae type b, Neisseria meningitidis and Streptococcus pneumoniae. Vaccine. 2008;26(35):4434-45.

6. McCarthy PC, Sharyan A, Sheikhi Moghaddam L. Meningococcal Vaccines: Current Status and Emerging Strategies. Vaccines (Basel). 2018;6(1):1-13. https://doi.org/10.1186/s12889-020-09946-1.

7. Trotter CL, Ramsay ME. Vaccination against meningococcal disease in Europe: review and recommendations for the use of conjugate vaccines. FEMS Microbiol Rev. 2007;31(1):101-7.

8. Stoof SP, Rodenburg GD, Knol MJ, Rumke LW, Bovenkerk S, Berbers GA, Spanjaard L, van der Ende A, Sanders EA. Disease Burden of Invasive Meningococcal Disease in the Netherlands Between June 1999 and June 2011: A Subjective Role for Serogroup and Clonal Complex. Clin Infect Dis. 2015;61(8):1281-92.

9. Steindl G, Liu YL, Schmid D, Orendi U, Kormann-Klement A, Heuberger S. Epidemiology of invasive meningococcal disease in Austria 2010. Wien Klin Wochenschr. 2011;123(Suppl 1):10-4.

10. Pollard AJ, Green C, Sadarangani M, Snape MD. Adolescents need a booster of serogroup $C$ meningococcal vaccine to protect them and maintain population control of the disease. Arch Dis Child. 2013;98(4):248-51.

11. Stefanelli $P$, Rezza G. Impact of vaccination on meningococcal epidemiology. Human Vaccines Immunotherapeutics. 2016;12(4):1051-5.

12. Vaccine Scheduler | ECDC | Meningococcal Disease: Recommended vaccinations [https://vaccine-schedule.ecdc.europa.eu/Scheduler/ ByDisease? SelectedDiseaseld $=48 \&$ Selected CountryldByDisease $=-1]$

13. Trotter $C L$, Maiden MC. Meningococcal vaccines and herd immunity: lessons learned from serogroup $C$ conjugate vaccination programs. Expert Rev Vaccines. 2009;8(7):851-61.

14. ECDC | Rapid Risk Assessment | Invasive meningococcal disease among men who have sex with men, July 2013. In.; 2013.

15. Aubert L, Taha M, Boo N, Le Strat Y, Deghmane AE, Sanna A, Barret AS, Levy-Bruhl D, Vandentorren S, Parent du Chatelet I. Serogroup C invasive meningococcal disease among men who have sex with men and in gayoriented social venues in the Paris region. Euro Surveillance. 2014;20(3). http://www.eurosurveillance.org/NiewArticle.aspx?Articleld=21016A.

16. Kratz MM, Weiss D, Ridpath A, Zucker JR, Geevarughese A, Rakeman J, Varma JK. Community-Based Outbreak of Neisseria meningitidis Serogroup C Infection in Men who Have Sex with Men, New York City, New York, USA, 2010-2013. Emerg Infect Dis. 2015;21(8):1379-86.

17. Nanduri S, Foo C, Ngo V, Jarashow C, Civen R, Schwartz B, Holguin J, Shearer E, Zahn M, Harriman K, et al. Outbreak of Serogroup C Meningococcal Disease Primarily Affecting Men Who Have Sex with Men - Southern California, 2016. MMWR Morb Mortal Wkly Rep. 2016;65(35):939-40.

18. Acevedo R, Bai X, Borrow R, Caugant DA, Carlos J, Ceyhan M, Christensen H, Climent Y, De Wals P, Dinleyici EC, et al. The Global Meningococcal Initiative meeting on prevention of meningococcal disease worldwide: Epidemiology, surveillance, hypervirulent strains, antibiotic resistance and high-risk populations. Expert Rev Vaccines. 2019;18(1):15-30. 
19. Hanquet $G$, Valenciano M, Simondon F, Moren A. Vaccine effects and impact of vaccination programmes in post-licensure studies. Vaccine. 2013; 31(48):5634-42.

20. Balmer $\mathrm{P}$, Borrow R, Miller E. Impact of meningococcal $C$ conjugate vaccine in the UK. J Med Microbiol. 2002;51(9):717-22.

21. Miller E, Salisbury D, Ramsay M. Planning, registration, and implementation of an immunisation campaign against meningococcal serogroup $C$ disease in the UK: a success story. Vaccine. 2001;20(Suppl 1):S58-67.

22. Ramsay ME, Andrews NJ, Trotter CL, Kaczmarski EB, Miller E. Herd immunity from meningococcal serogroup $C$ conjugate vaccination in England: database analysis. BMJ (Clinical research ed). 2003;326(7385):365-6.

23. Trotter $\mathrm{CL}$, Ramsay ME, Kaczmarski EB. Meningococcal serogroup C conjugate vaccination in England and Wales: coverage and initial impact of the campaign. Commun Dis Public Health. 2002;5(3):220-5.

24. Stanton MC, Taylor-Robinson D, Harris D, Paize F, Makwana N, Hackett SJ, Baines PB, Riordan FA, Marzouk O, Thomson AP, et al. Meningococcal disease in children in Merseyside, England: a 31 year descriptive study. PLoS One. 2011;6(10):e25957.

25. Gray SJ, Trotter CL, Ramsay ME, Guiver M, Fox AJ, Borrow R, Mallard RH, Kaczmarski EB. Epidemiology of meningococcal disease in England and Wales 1993/94 to 2003/04: contribution and experiences of the Meningococcal Reference Unit. J Med Microbiol. 2006;55(Pt 7):887-96.

26. Bose A, Coen P, Tully J, Viner R, Booy R. Effectiveness of meningococcal C conjugate vaccine in teenagers in England. Lancet (London, England). 2003; 361(9358):675-6

27. Campbell H, Andrews N, Borrow R, Trotter C, Miller E. Updated postlicensure surveillance of the meningococcal $\mathrm{C}$ conjugate vaccine in England and Wales: effectiveness, validation of serological correlates of protection, and modeling predictions of the duration of herd immunity. Clin Vaccine Immunol. 2010;17(5):840-7.

28. Mooney JD, Christie P, Robertson C, Clarke SC. The impact of meningococcal serogroup C conjugate vaccine in Scotland. Clin Infect Dis. 2004;39(3):349-56.

29. Ramsay ME, Andrews N, Kaczmarski EB, Miller E. Efficacy of meningococcal serogroup $C$ conjugate vaccine in teenagers and toddlers in England. Lancet (London, England). 2001;357(9251):195-6.

30. Trotter CL, Andrews NJ, Kaczmarski EB, Miller E, Ramsay ME. Effectiveness of meningococcal serogroup $C$ conjugate vaccine 4 years after introduction. Lancet (London, England). 2004;364(9431):365-7.

31. Cano R, Larrauri A, Mateo S, Alcala B, Salcedo C, Vazquez JA. Impact of the meningococcal C conjugate vaccine in Spain: an epidemiological and microbiological decision. Euro Surveillance. 2004;9(7):5-6.

32. Garrido-Estepa M, Leon-Gomez I, Herruzo R, Cano R. Changes in meningococcal $C$ epidemiology and vaccine effectiveness after vaccine introduction and schedule modification. Vaccine. 2014;32(22):2604-9.

33. Salleras $L$, Dominguez A, Cardenosa N. Dramatic decline of serogroup C meningococcal disease in Catalonia (Spain) after a mass vaccination campaign with meningococcal C conjugated vaccine. Vaccine. 2003;21(7-8):729-33.

34. Morales D, Garcia-Cenoz M, Moreno L, Bernaola E, Barricarte A. Castilla J: [Meningococcal C conjugate vaccine: Impact of a vaccination program and long-term effectiveness in Navarra, Spain, 2000-2014]. Enfermedades Infec Microbiol Clin. 2016;34(10):639-44.

35. Rego Romero E, Nartallo Penas V, Taboada Rodriguez JA, Malvar Pintos A, Hervada Vidal X, Lopez Pimentel MJ. Implementation and impact of a meningococcal $C$ conjugate vaccination program in 13 - to 25 -year-old individuals in Galicia, Spain. Z Gesundh Wiss. 2011;19(5):409-15.

36. Cruz Rojo C, Garcia Gil C, Nieto Vera J, Monroy Morcillo A. Impact of systematic vaccination with the antimeningococcal $C$ conjugated vaccine in a health area in Andalusia. Rev Esp Salud Publica. 2005;79(6):655-63.

37. Martinez Al, Dominguez A, Oviedo M, Minguell S, Jansa JM, Codina G, Vazquez JA. Changes in the evolution of meningococcal disease, 2001-2008, Catalonia (Spain). Vaccine. 2009;27(25-26):3496-8.

38. Garrido-Estepa M, Nunez OG, Leon-Gomez I, Cano R, Herruzo R. Meningococcal $C$ conjugate age-dependant long-term loss of effectiveness. Vaccine. 2015;33(19):2221-7.

39. Larrauri A, Cano R, Garcia M, Mateo S. Impact and effectiveness of meningococcal $C$ conjugate vaccine following its introduction in Spain. Vaccine. 2005;23(32):4097-100.

40. Salleras L, Dominguez A, Cardenosa N. Impact of mass vaccination with polysaccharide conjugate vaccine against serogroup $\mathrm{C}$ meningococcal disease in Spain. Vaccine. 2003;21(7-8):725-8.
41. Bettinger JA, Scheifele DW, Le Saux N, Halperin SA, Vaudry W, Tsang R. The impact of childhood meningococcal serogroup C conjugate vaccine programs in Canada. Pediatr Infect Dis J. 2009;28(3):220-4.

42. Kinlin LM, Jamieson F, Brown EM, Brown S, Rawte P, Dolman S, Drews SJ, Fisman DN. Rapid identification of herd effects with the introduction of serogroup C meningococcal conjugate vaccine in Ontario, Canada, 20002006. Vaccine. 2009;27(11):1735-40.

43. Siu T, Tang W, Dawar M, Patrick DM. Impact of routine immunization using meningococcal $\mathrm{C}$ conjugate vaccine on invasive meningococcal disease in British Columbia. Can J Public Health. 2008;99(5):380-2.

44. Sadarangani M, Scheifele DW, Halperin SA, Vaudry W, Le Saux N, Tsang R, Bettinger JA. The impact of the meningococcal serogroup $C$ conjugate vaccine in Canada between 2002 and 2012. Clin Infect Dis. 2014;59(9):1208-15.

45. De Wals P, Deceuninck G, Lefebvre B, Boulianne N, De Serres G. Effectiveness of serogroup $C$ meningococcal conjugate vaccine: a 7-year follow-up in Quebec, Canada. Pediatr Infect Dis J. 2011;30(7):566-9.

46. Andrade AL, Minamisava R, Tomich LM, Lemos AP, Gorla MC, de Cunto Brandileone MC, Domingues CM, de Moraes C, Policena G, Bierrenbach AL. Impact of meningococcal $\mathrm{C}$ conjugate vaccination four years after introduction of routine childhood immunization in Brazil. Vaccine. 2017;35(16):2025-33.

47. Cardoso CW, Pinto LL, Reis MG, Flannery B, Reis JN. Impact of vaccination during an epidemic of serogroup C meningococcal disease in Salvador, Brazil. Vaccine. 2012;30(37):5541-6.

48. Tauil Mde C, Carvalho CS, Vieira AC, Waldman EA. Meningococcal disease before and after the introduction of meningococcal serogroup $C$ conjugate vaccine. Federal District, Brazil. Braz J Infect Dis. 2014;18(4):379-86.

49. Cardoso CW, Ribeiro GS, Reis MG, Flannery B, Reis JN. Effectiveness of meningococcal C conjugate vaccine in Salvador, Brazil: a case-control study. PLoS One. 2015;10(4):e0123734.

50. Stefanelli P, Fazio C, Sofia T, Neri A, Mastrantonio P. Serogroup C meningococci in Italy in the era of conjugate menC vaccination. BMC Infect Dis. 2009:9:135.

51. de Waure C, Miglietta A, Nedovic D, Mereu G, Ricciardi W. Reduction in Neisseria meningitidis infection in Italy after Meningococcal C conjugate vaccine introduction: A time trend analysis of 1994-2012 series. Human Vaccines Immunotherapeutics. 2016;12(2):467-73.

52. Neri A, Pezzotti P, Fazio C, Vacca P, D'Ancona FP, Caporali MG, Stefanelli P. Epidemiological and Molecular Characterization of Invasive Meningococcal Disease in Italy, 2008/09-2012/13. PLoS One. 2015;10(10):e0139376.

53. Pascucci MG, Di Gregori V, Frasca G, Rucci P, Finarelli AC, Moschella $L$, Borrini BM, Cavrini F, Liguori G, Sambri V, et al. Impact of meningococcal C conjugate vaccination campaign in Emilia-Romagna, Italy. Human Vaccines Immunotherapeutics. 2014;10(3):671-6.

54. Chiu C, Dey A, Wang H, Menzies R, Deeks S, Mahajan D, Macartney K,

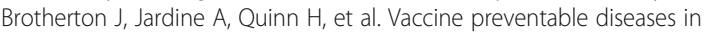
Australia, 2005 to 2007. Commun Dis Intell Q Rep. 2010;34(Supp):S1-167.

55. Lawrence GL, Wang H, Lahra M, Booy R, Mc IP. Meningococcal disease epidemiology in Australia 10 years after implementation of a national conjugate meningococcal C immunization programme. Epidemiol Infect. 2016;144(11):2382-91.

56. Bijlsma MW, Bekker V, Brouwer MC, Spanjaard $L$, van de Beek $D$, van der Ende $A$. Epidemiology of invasive meningococcal disease in the Netherlands, 1960-2012: an analysis of national surveillance data. Lancet Infect Dis. 2014;14(9):805-12.

57. Bijlsma MW, Brouwer MC, Spanjaard L, van de Beek D, van der Ende A. A decade of herd protection after introduction of meningococcal serogroup $C$ conjugate vaccination. Clin Infect Dis. 2014;59(9):1216-21.

58. Hellenbrand W, Elias J, Wichmann O, Dehnert M, Frosch M, Vogel U. Epidemiology of invasive meningococcal disease in Germany, 2002-2010, and impact of vaccination with meningococcal C conjugate vaccine. J Inf Secur. 2013;66(1):48-56.

59. Mattheus W, Hanquet G, Collard JM, Vanhoof R, Bertrand S. Changes in Meningococcal Strains in the Era of a Serogroup C Vaccination Campaign: Trends and Evolution in Belgium during the Period 1997-2012. PLoS One. 2015;10(10):e0139615.

60. Cano R, Larrauri A, Mateo S, Alcala B, Salcedo C, Vazquez JA. Impact of the meningococcal $C$ conjugate vaccine in Spain: an epidemiological and microbiological decision. Euro Surveillance. 2004;9(7):11-5.

61. De Wals P, De Serres G, Niyonsenga T. Effectiveness of a mass immunization campaign against serogroup C meningococcal disease in Quebec. Jama. 2001;285(2):177-81. 
62. van Ravenhorst MB, van der Klis FRM, van Rooijen DM, Knol MJ, Stoof SP, Sanders EAM, Berbers GAM. Meningococcal serogroup C immunogenicity, antibody persistence and memory B-cells induced by the monovalent meningococcal serogroup $C$ versus quadrivalent meningococcal serogroup ACWY conjugate booster vaccine: A randomized controlled trial. Vaccine. 2017;35(36):4745-52.

63. Lopalco PL, DeStefano F. The complementary roles of Phase 3 trials and post-licensure surveillance in the evaluation of new vaccines. Vaccine. 2015; 33(13):1541-8.

64. Cohn AC, MacNeil JR, Harrison LH, Lynfield R, Reingold A, Schaffner W, Zell ER, Plikaytis B, Wang X, Messonnier NE. Effectiveness and Duration of Protection of One Dose of a Meningococcal Conjugate Vaccine. Pediatrics. 2017;139(2).

65. Andrews N, Borrow R, Miller E. Validation of serological correlate of protection for meningococcal $\mathrm{C}$ conjugate vaccine by using efficacy estimates from postlicensure surveillance in England. Clin Diagn Lab Immunol. 2003;10(5):780-6.

66. Perrett KP, Jin C, Clutterbuck E, John TM, Winter AP, Kibwana E, Yu LM, Curtis N, Pollard AJ. B cell memory to a serogroup C meningococcal conjugate vaccine in childhood and response to booster: little association with serum IgG antibody. J Immunol. 2012;189(5):2673-81.

67. Kelly DF, Moxon ER, Pollard AJ. Haemophilus influenzae type b conjugate vaccines. Immunology. 2004;113(2):163-74.

68. Heath PT, McVernon J. The UK Hib vaccine experience. Arch Dis Child. 2002; 86(6):396-9.

69. Moreno-Perez D, Alvarez Garcia FJ, Alvarez Aldean J, Cilleruelo Ortega MJ, Garces Sanchez M, Garcia Sanchez N, Hernandez Merino A, Mendez Hernandez M, Merino Moina M, Montesdeoca Melian A, et al. Immunisation schedule of the Spanish Association of Paediatrics: 2019 recommendations. An Pediatr. 2019;90(1):56.e51-9.

70. Invasive meningococcal disease in England: annual report for 2017 to 2018 supplementary data tables. In. Edited by England PH; 2018: https://assets. publishing.service.gov.uk/government/uploads/system/uploads/attachment_ data/file/841717/Laboratory_confirmed_cases_of_IMD_England_data_ tables_2018.pdf.

71. Australian Government DoH. Invasive meningococcal disease, National surveillance report. In: Australian Government, Department of Health, vol. $84 ; 2017$.

72. Knol MJ et al. Meningococcal disease in the Netherlands. Background information for the Health Council. RIVM Report 2017, vol. 58; 2017.

73. Les infections invasives à méningocoques en 2017. In.: Agence nationale de santé publique.; 2017: 15.

74. Calendrier des vaccinations et recommandations vaccinales 2019. In. Edited by santé Dgdl: Ministère des Solidarités et de la Santé; 2019: 73.

75. Pezzotti P, Miglietta A, Neri A, Fazio C, Vacca P, Voller F, Rezza G, Stefanelli P. Meningococcal $C$ conjugate vaccine effectiveness before and during an outbreak of invasive meningococcal disease due to Neisseria meningitidis serogroup C/cc11, Tuscany, Italy. Vaccine. 2018;36(29):4222-7.

76. Booy R, Gentile A, Nissen M, Whelan J, Abitbol V. Recent changes in the epidemiology of Neisseria meningitidis serogroup $W$ across the world current vaccination policy choices and possible future strategies. Human Vaccines Immunother. 2019;15(2):470-80.

77. Knol MJ, Ruijs WL, Antonise-Kamp L, de Melker HE, van der Ende A. Implementation of MenACWY vaccination because of ongoing increase in serogroup W invasive meningococcal disease, the Netherlands, 2018. Euro Surveill. 2018;23(16). https://doi.org/10.2807/1560-7917.ES.2018.23.16.18-00158.

78. Centers for Disease Control and Prevention (CDC) Advisory Committee on Immunization Practices. Revised recommendations of the Advisory Committee on Immunization Practices to Vaccinate all Persons Aged 11-18 Years with Meningococcal Conjugate Vaccine. MMWR Morb Mortal Wkly Rep. 2007;56(31):794-5.

79. Cohn AC, MacNeil JR, Clark TA, Ortega-Sanchez IR, Briere EZ, Meissner HC, Baker CJ, Messonnier NE. Prevention and control of meningococcal disease: recommendations of the Advisory Committee on Immunization Practices (ACIP). MMWR Recomm Rep. 2013;62(Rr-2):1-28.

80. Greco T, Zangrillo A, Biondi-Zoccai G, Landoni G. Meta-analysis: pitfalls and hints. Heart Lung Vessel. 2013;5(4):219-25.

81. Cohen R, Levy C. Meningococcal vaccines: from polysaccharide to conjugate vaccines. Arch Pediatr. 2012;19:S61-4.

82. Southern J, Borrow R, Andrews N, Morris R, Waight P, Hudson M, Balmer P, Findlow $\mathrm{H}$, Findlow J, Miller $\mathrm{E}$. Immunogenicity of a reduced schedule of meningococcal group C conjugate vaccine given concomitantly with the Prevenar and Pediacel vaccines in healthy infants in the United Kingdom. Clin Vaccine Immunol. 2009;16(2):194-9.

83. Borrow R, Andrews N, Findlow H, Waight P, Southern J, Crowley-Luke A, Stapley L, England A, Findlow J, Miller E. Kinetics of antibody persistence following administration of a combination meningococcal serogroup $C$ and haemophilus influenzae type $b$ conjugate vaccine in healthy infants in the United Kingdom primed with a monovalent meningococcal serogroup C vaccine. Clin Vaccine Immunol. 2010;17(1):154-9.

\section{Publisher's Note}

Springer Nature remains neutral with regard to jurisdictional claims in published maps and institutional affiliations.
Ready to submit your research? Choose BMC and benefit from:

- fast, convenient online submission

- thorough peer review by experienced researchers in your field

- rapid publication on acceptance

- support for research data, including large and complex data types

- gold Open Access which fosters wider collaboration and increased citations

- maximum visibility for your research: over $100 \mathrm{M}$ website views per year

At BMC, research is always in progress.

Learn more biomedcentral.com/submissions 